\title{
TEATRO Y TRADUCCIÓN A LAS PUERTAS DEL ROMANTICISMO: PRESENCIA DE TRAGEDIAS DE VOLTAIRE DURANTE EL TRIENIO CONSTITUCIONAL ${ }^{\natural}$
}

\author{
Francisco LAFARGA \\ Universidad de Barcelona
}

El Trienio Constitucional es una de las épocas más convulsionadas de la historia de España aunque, al mismo tiempo, y no obstante su brevedad -de marzo de 1820 (jura por Fernando VII de la Constitución de 1812) hasta octubre de 1823 (liberación del rey en Cádiz por las tropas francesas del duque de Angulema)resulta un tiempo apasionante por el movimiento literario que suscitó. La supresión de la rígida censura fernandina por un lado y la repercusión literaria de los acontecimientos políticos e incluso militares por otro, dieron lugar a una variada y copiosa literatura, no siempre de primer orden, pero en cualquier caso siempre viva y palpitante.

El teatro fue, una vez más, lugar privilegiado de plasmación de estas circunstancias y termómetro de la actualidad.

La mayoría de piezas que se representaron o publicaron fueron obras de circunstancias para conmemorar fechas y sucesos gloriosos, airear el debate constitucional o plasmar las disputas acérrimas entre serviles y liberales; también se pusieron en escena obras estrenadas previamente, refundiciones y traducciones

' Este trabajo se ha realizado en el marco del proyecto de investigación BFF2003-02569, del Ministerio de Educación y Ciencia, cofinanciado con fondos FEDER. El autor es, asimismo, investigador principal del TRELIT-Traducción y recepción de las literaturas, grupo de investigación consolidado de la Generalitat de Catalunya (2001SGR00005). Vid. una primera versión de este trabajo (2004, págs. 145-152). 
que contribuian a crear un estado de opinión: así, pudieron verse de nuevo en las tablas El Pelayo de Quintana, La viuda de Padilla de Martínez de la Rosa, Juan de Calás de Chénier o Roma libre de Alfieri (véase Freire 1997, págs. 294-297; Gies 1996, págs. 91-94; Lafarga 1991). ${ }^{2}$

En este contexto se sitúan distintas traducciones de tragedias de Voltaire, en particular La muerte de César, a la que me referiré más adelante. La supresión del tribunal de la Inquisición dejaba sin efecto la dura prohibición que pesaba sobre las obras de Voltaire desde 1762 (véase Lafarga 1989, págs. 28-49). Este hecho no está desde luego, ausente de la notoria presencia de obras volterianas -tragedias y de otro tipo- en la bibliografía española. Y en muchos casos (no en todos, justo es reconocerlo), tales obras están cumpliendo un cometido netamente político o ideológico. ${ }^{3}$

Así, el mismo traductor, Tomás Bertrán y Soler, dio en 1821 su versión de Le fanatisme ou Mahomet le prophète con el escueto y significativo título de $E l$ fanatismo, mientras que el año siguiente apareció su traducción de Alzira. ${ }^{4}$ En ambos casos se menciona la autoría de Voltaire, aunque el traductor no ha introducido paratexto alguno en el que manifieste su posición.

Podría afirmarse que es igualmente «inocua»-si puede serlo una pieza de Voltaire- la edición, denominada $5^{\mathrm{a}}$, de la pieza más conocida de su autor: Zaïre, debida a Vicente García de la Huerta (1784) y que este tituló La fe triunfante del amor y cetro.

No ocurre lo mismo con la traducción del Brutus volteriano debida al conde de Teba, que lo fue luego del Montijo, tío de la futura emperatriz de los franceses, personaje de talante liberal manifestado en sus actitudes y en sus escritos. Aunque en la propia portada de la obra se declara que la traducción estaba lista ya en 1805 , no apareció hasta 1820 en una edición murciana, con un prólogo de cierto B. F. C., amigo del conde, que aparentemente había corregido la pieza. En dicho prólogo, dedicado «Al pueblo español», pueden leerse varias frases de exaltado patriotismo y liberalismo:

2 En el teatro de Barcelona, por ejemplo, se representaron en este período traducciones que habían sido prohibidas con anterioridad, como el Tartuffe de Molière en la versión de Marchena titulada El hipócrita o las Victimes cloitrées de Boutet de Monvel, seguramente en la versión de Carnerero (véase Suero 1990 , III, págs. 183 y 169 , respectivamente).

${ }^{3}$ Para las traducciones españolas de Voltaire me permito remitir a las páginas de mi libro Voltaire en España (Barcelona, Universidad de Barcelona, 1982) y, mejor, a su versión francesa corregida y aumentada Voltaire en Espagne (Oxford, The Voltaire Foundation, 1989): tanto en uno como en otro se encuentra el catálogo de traducciones y, en el lugar correspondiente, el comentario de la traducción.

${ }^{4}$ Al final de este trabajo podrán encontrarse las referencias completas de las traducciones mencionadas. 
Ojalá se consiga el objeto de este trabajo, ojalá no olvides nunca que Si un pueblo libre es, se hace invencible.

Esto te hará amar la libertad: con ella adquirirás la gloria que habías perdido y aún más libre y más noble que los mismos romanos, irás a las naciones, no a sojuzgarlas como aquellos, sino a libertarlas de los tiranos. A ti vendran los pueblos oprimidos y tú, no desmintiendo la heroicidad y dulce carácter español, digno siempre de este nombre, serás el terror de los déspostas. El universo te bendecirá; esta es la verdadera gloria: sigue la marcha que emprendiste y la conseguirás (pág. 4).

Cuando, dos años más tarde, se publicó la segunda edición, fue el propio traductor quien redactó una dedicatoria de tono muy parecido a la de su amigo:

Al pueblo español. El deseo de extender en el pueblo español ciertas verdades de que depende su felicidad me hizo emprender esta traducción, sin arredrarme tamaña empresa, persuadido de que siempre quedarían grabados en el corazón de mis compatriotas los dogmas políticos en que se funda su bienestar. [...] Seguro, pues, de que no ha sido enteramente inútil mi trabajo, me he animado a hacer esta segunda impresión. Plegue al cielo contribuya eficazmente a inspirar a mis compatriotas el horror al despotismo en cualquier especie de gobierno, pues no hay alguno, por libre que sea, que borre del hombre la idea de sobreponerse a los demás, si le es posible (pág. 3).

Con todo, la traducción más interesante por sus circunstancias y sus implicaciones políticas de todo este periodo es la de La muerte de César, realizada por Francisco Altés y Casals (o Altés y Gurena) en 1823. Para empezar, la personalidad de Altés, poeta y traductor, que a la sazón era secretario del Ayuntamiento constitucional de Barcelona y miembro de la Academia de Buenas Letras de la capital catalana, y que en 1824 tuvo que partir al exilio por sus compromisos políticos. Creo que es una figura no suficientemente estudiada del mundillo cultural barcelonés de los años 1820-1830. La mención más amplia es la que aparece en la bibliografía de Elías de Molins (1889, págs. 37-47); en los demás repertorios que he consultado las menciones son bastante breves: véase Corminas 1973, págs. 9-10; Menarini 1982, págs. 26 y passim; Herrera 1993, págs. 12-14; Rodríguez Sánchez 1994, pág. 46.

Dejando a un lado su copiosa labor traductora, me detendré únicamente en su versión de la tragedia de Voltaire. La muerte de César no era la primera vez que se traducía al español; puede recordarse especialmente otra versión anterior (de 1791) que armó no poco revuelo, aunque no tanto porque en su portada apareciera el nombre de Voltaire, sino porque su autor arremetía en el prólogo contra los actores españoles y el modo de representar vigente en aquel momento en España. El caso es que la pieza fue prohibida por la Inquisición en 1796 y su traductor (que 
estaba iniciando una fulgurante carrera política que le llevaría hasta el ministerio) pudo salvarse de una dura condena gracias a la protección del conde de Aranda.

La misma tragedia, por otra parte, aparece como ejemplo de la importancia de la traducción como modelo literario o como fuente de inspiración de los autores en un pasaje del célebre apologista de la religión católica Rafael de Vélez, quien arremetiendo contra la Oda a Padilla de Quintana, alude a la pieza deVoltaire:

¿Qué identidad de sentimientos! No parece sino que los papeles de Volter (sic) fueron el modelo de esta composición dedicada a Juan Padilla. Se copian las frases, la dicción, su estilo, el fủego, los términos, «vengar la patria, heroísmo, derramar la sangre, sacudir la esclavitud, romper las cadenas de los reyes, su despotismo y tiranía». Estas voces llenan todos los versos, estos rasgos ocupan todas las páginas. ¡A A ! Las plumas de Volter y de Q... no escriben sino con sangre. Un veneno el más mortífero confecciona sus tintas: el que las lea se contagia. Odio implacable a todo rey y un amor desenfrenado a la libertad: he aquí lo que respiran las dos composiciones. Si La muerte de César y la tragedia de Bruto no hubieran venido a España, Juan Padilla acaso no hubiera visto la luz pública (Vélez 1816, II, pág. 29).

La traducción de La muerte de César por Altés se estrenó en el teatro de Barcelona el 30 de mayo de 1823. En el anuncio correspondiente del Diario de Barcelona podía leerse:

La tragedia en tres actos titulada La muerte de César; seguirá el baile de la sinfonía oriental y se dará fin con el sainete titulado El ardid contra la fuerza. A las siete y media. Con motivo de ser los días de nuestro Rey constitucional el teatro estará iluminado y la entrada a tres reales.

Nota: La dicha tragedia se halla de venta en la oficina de la viuda Roca, en la de Narcisa Dorca y en la puerta del coliseo, con la variación en el final según va a representarse en el teatro.

En la edición de la tragedia, hecha por la viuda Roca, aparece el final según el texto de Voltaire y a continuación (págs. 55-57) la última escena según se iba a ejecutar en el teatro. La modificación introducida no es totalmente inocente, a pesar de lo que se dice en un manuscrito de la traducción conservado en la Biblioteca de Catalunya:

Este es el modo con que dio fin a esta tragedia su autor Mr. de Voltaire; no obstante, bajo la dirección del ciudadano primer actor D. Andrés Pricto se ejecutó el final en el teatro de Barcelona de otro modo, no del todo diferente, sino que se puede decir un compendio o resumen del original.

En efecto, el cambio me parece sustancial. En la última escena del original Antonio, tras hacer el panegírico de César en un alarde de cinismo, exhorta a los romanos a perseguir a sus asesinos y logra convencerlos: 


\begin{abstract}
Antoine. Réveillez-vous, Romains
Marchez, suivez-moi tous contre ses assassins:

Ce sont-là les honneurs qu'à César on doit rendre.

Des brandons du bûcher qui va le mettre en cendre,

Embrasons les palais de ces fiers conjurés:

Enfonçons dans leur sein nos bras désespérés.

Venez, dignes amis; venez, vengeurs des crimes,

Aux dieux de la patrie immoler ces victimes.

Romains. Oui, nous les punirons; oui, nous suivrons vos pas.

Nous jurons par son sang de venger son trépas.

Courons.

Antoine (à Dolabelle). Ne laissons pas leur fureur inutile;

Précipitons ce peuple inconstant et facile:

Entraînons-le à la guerre; et, sans rien ménager,

Succédons à César en courant le venger. (III, 8)
\end{abstract}

En la modificación introducida, Cimbro, uno de los conjurados, ataja las palabras de Antonio al pueblo:

$\begin{array}{ll}\text { Cimbro. } & \text { Baste, romanos, } \\ & \text { Baste de seducción, os habla Cimbro } \\ \text { Y no debéis dudar de sus palabras; } & \text { Tesoros os ofrecen los inicuos } \\ & \text { Para dorar la esclavitud odiosa. } \\ & \text { Ya sabemos que César fue benigno, } \\ & \text { Pero también sabemos que el matarle } \\ & \text { Nos dio la libertad. Si arrepentidos, } \\ & \text { Romanos, os halláis, tenéis aceros } \\ & \text { Traspasad nuestros pechos aquí mismo, } \\ & \text { Y aceptad las cadenas que os preparan. } \\ & \text { Nosotros por no vernos oprimidos } \\ & \text { Clamando libertad exhalaremos } \\ & \text { Sin inmutarnos el postrer suspiro. } \\ \text { Romanos. } & \text { No, vivid todos, libertad queremos. } \\ \text { Otros. } & \text { Nunca, nunca despótico dominio. } \\ \text { Romanos. } & \text { Libertad o la muerte. } \\ \text { Cimbro. } & \text { Ciudadanos, } \\ \text { Retirad, pues, ese cadáver frío, } & \text { Y si otro César se presenta en Roma, } \\ & \text { Imitemos a Bruto en su heroísmo. }\end{array}$

Como puede comprobarse, la diferencia introducida por la modificación del desenlace es mucho más que de simple matiz. Parece, en efecto, difícil que una 
conciencia liberal como la de Altés ${ }^{5}$ hubiera podido concebir que el final de una pieza en la que se combatía la tiranía y el despotismo se resolviera con la muerte de los defensores de la libertad y la democracia.

La pieza se representó tres días seguidos, obteniéndose unos ingresos bastante elevados, más significativos el día del estreno por el precio algo más elevado de las localidades, como era natural cuando había función extraordinaria (véase Suero 1990, III, pág. 271). Obsérvese de paso la ironía que representa ir a dar semejante obra el día del santo de Fernando VII.

La muerte de César, suponemos que con el mismo desenlace, fue el centro de una completa función patriótica celebrada el 24 de septiembre de 1823 y que en el Diario de Barcelona se anunció del siguiente modo:

Deseosa la comisión directiva de este coliseo de contribuir al laudable objeto de solemnizar el aniversario de la instalación de las Cortes generales y extraordinarias en Cádiz en 1810, nada ha omitido para conseguirlo, a cuyo fin presenta hoy la siguiente función. Se dará principio con una bella sinfonía, a la que seguirá inmediatamente la enérgica tragedia de Voltaire, traducida por el ciudadano Altés, titulada La muerte de César, ensayada por el señor Prieto y desempeñando en ella la señora Molina la hermosa parte de Bruto; enseguida se bailará el Caballito o Los majos de Cádiz, cuyo final serán las boleras a doce. Concluido el bailete todos los actores de cantado disponibles de la compañía española se presentarán luego a entonar himnos y canciones patrióticas; a continuación la señora Molina, en traje de miliciana y con la enérgica valentía con que reproduce las máximas liberales y las invectivas contra los tiranos, recitará una poesia nueva compuesta por el decidido patriota W. A. cuyo título es: El grito de Barcino, mientras las huestes enemigas amenazarán sus muros. $Y$ se dará fin a la función con la pieza de circunstancia, en un acto, titulada $E l$ alcalde liberal. (Suero 1990, III, pág. 288).

Otras obras de Voltaire, ${ }^{6}$ aunque también de muchos otros autores extranjeros que, por un motivo u otro, fueron consideradas peligrosas o subversivas en los años precedentes pudieron ver la luz o ser representadas sin problemas de censura durante el breve Trienio Constitucional y, por el mismo motivo, desaparecieron durante los años siguientes. Un estudio sistemático de lo publicado en ese perío-

${ }^{5}$ Aunque tanto en el manuscrito como en la edición se menciona la «dirección del ciudadano primer actor Andrés Prieto», bajo la cual se habria llevado la representación «modificada», no me parecen atribuibles a éste los cambios introducidos y sí exclusivamente al traductor.

"Vieron la luz en este período: La Enriada (Madrid, 1821) por José Joaquín de Virués, comandante político de Sevilla en 1821; La doncella de Orleans, por traductor anónimo, con pie de imprenta en las Batuecas, Imprenta de la Libertad, sin año, aunque anterior a una nueva edición de 1824; las Novelas en traducción de Marchena (Burdeos, 1822); un volumen misceláneo de Filosofia (Madrid, 1822), y dos ediciones (Madrid, 1821 y 1822) de los Comentarios sobre el libro de los Delitos y de las penas, ambas obras de traductor desconocido. 
do, con el oportuno cotejo con las etapas anterior y posterior -período absolutista de Fernando VII y Ominosa Década- arrojaría mucha luz no sólo sobre los efectos de la censura sino sobre el papel de las traducciones como portadoras de una carga política e ideológica. 


\section{BIBLIOGRAFÍA}

\section{TRADUCCIONES MENCIONADAS}

Alzira, tragedia en cinco actos en verso; escrita en francés por Voltaire, traducida en español por el ciudadano T. Bertrán, Barcelona, José Torner, 1822, 83 págs, $15 \mathrm{~cm}$.

Bruto. Tragedia en cinco actos, traducida por el Excmo. Sr. Conde de Teba, en el año de 1805, y corregida por D. B. F. C. su amigo, Murcia, Imprenta de Mariano Bellido, 1820, 101 págs., $19 \mathrm{~cm}$.

Bruto. Tragedia en cinco actos, traducida por el Excmo. Sr. Conde del Montijo, el año de 1805. Segunda edición, Madrid, imprenta Calle de la Greda, 1822, 95 págs., $19 \mathrm{~cm}$.

El Fanatismo. Tragedia en cinco actos, escrita en francés por Voltaire, traducida en castellano por D. T. B. y S. (Al fin:) Barcelona, Imprenta de José Torner, 1821,30 págs., $21 \mathrm{~cm}$.

La Fe triunfante del amor y cetro o Xayra. Tragedia francesa. Traducida al español por Don Vicente García de la Huerta, de la Academia Española. Quinta edición. (Al fin:) Barcelona, Imprenta de José Torner, 1821, 26 págs., 21 $\mathrm{cm}$.

La muerte de César. Tragedia francesa de Mr. de Voltaire, traducida en verso castellano y acompañada de un Discurso del traductor sobre el estado actual de nuestros teatros y necesidad de su reforma. Por Don Mariano Luis de Urquijo, Madrid, Blas Román, 1791, 10+87+150 págs., $15,5 \mathrm{~cm}$.

La muerte de César. Tragedia de Voltaire en tres actos, traducida por el ciudadano Don Francisco Altés, socio de la Academia de Buenas Letras de la ciudad de Barcelona y secretario de su Excmo. Ayuntamiento constitucional, Barcelona, Imprenta de la Viuda Roca, 1823, 54 págs., $15 \mathrm{~cm}$.

\section{REFERENCIAS BIBLIIOGRÁFICAS}

CORMINAS, Joan, [1849] 1973. Suplemento a las memorias para ayudar a formar un diccionario crítico de los escritores catalanes, publicadas por el Excmo. e Ilmo. Sr. D. Félix Torres Amat, Barcelona, Curial.

Elías DE MOLINS, Antonio, 1889-1895. Diccionario biográfico y bibliográfico de escritores y artistas catalanes del siglo XIX, Barcelona, Imprenta Fidel Giró [ed. electrónica Pamplona, Analecta, 2000].

FREIRE, Ana María, 1997. «El teatro político durante el reinado de Fernando VII» en Guillermo CARNERO (ed.), Historia de la literatura española. Siglo XIX (I), Madrid, Espasa-Calpe, págs. 293-300. 
GIES, David T., 1996. El teatro en la España del siglo XIX, Cambridge, Cambridge University Press.

HERRERA, Jerónimo, 1993. Catálogo de autores teatrales del siglo XVIII, Madrid, Fundación Universitaria Española.

LAFARGA, Francisco, 1989. Voltaire en Espagne, 1734-1835, Oxford, The Voltaire Foundation (Studies on Voltaire and the Eighteenth Century, 261).

- 2004. «La muerte de César y otras tragedias de Voltaire publicadas durante el Trienio Liberal», Málaga, Miguel Gómez Ediciones, págs. 145-152.

- 1991. «Teatro político español (1805-1840): ensayo de un catálogo» en Ermanno CALDERA (ed.), Teatro politico spagnolo del primo Ottocento, Roma, Bulzoni, págs. 167-251.

Menarinl, Piero \& al., 1982. El teatro romántico español (1830-1850). Autores, obras, bibliografia, Bolonia, Atesa.

RodrígueZ SÁNCHeZ, Tomás, 1994. Catálogo de dramaturgos españoles del siglo XIX, Madrid, Fundación Universitaria Española.

RODRíGUeZ SÁNCHEZ DE LEÓN, Ma José, 1993. «Las traducciones del francés durante la Ominosa Década: el sentido de la traducción y su consideración crítica», Livius 4, págs. 191-203.

SUERO ROCA, Maria Teresa, 1990. El teatre representat a Barcelona de 1800 a 1830, Barcelona, Institut del Teatre, 4 vols.

Vélez, Rafael de, 1816. Apología del Altar y del Trono, Madrid, B. Cano, 2 vols. 